\title{
Utilization of Sweat Potato Starch Wastewater and Monosodium Glutamate Wastewater for Cultivation of an Anti-Fungal Biocontrol Agent Paenibacillus Polymyxa
}

\author{
Zhihui Bai ${ }^{1}$, Likun $\mathrm{Gu}^{1}$, Yanming $\mathrm{Su}^{1}$, Bo Jin ${ }^{2}$ and Guoqiang Zhuang1 \\ ${ }^{1}$ Research Centre for Eco-Environmental Sciences, \\ Chinese Academy of Sciences, Beijing 100085, \\ ${ }^{2}$ School of Earth and Environment Sciences, \\ the University of Adelaide, Adelaide, SA 5005, \\ ${ }^{1}$ China \\ ${ }^{2}$ Australia
}

\section{Introduction}

Effluents from monosodium glutamate manufacturing plants possess a high strength of COD (10,000--30,000 mg/l), ammonium (15,000--25,000 mg/l), sulphate (15,000--30,000 $\mathrm{mg} / \mathrm{l})$ and very low $\mathrm{pH}(<2)$ (Yang et al., 2005). Effluents from sweat potato starch industry contains a high load of protein, pectin, and starchy materials with the COD of 10,000 - 35,000 $\mathrm{mg} / \mathrm{l}$ (Mishra et al., 2004). Due to the low $\mathrm{pH}$, high concentration of COD, sufate and $\mathrm{NH}_{3}-$ $\mathrm{N}$, the treatment of such wastewaters by conventional activated sludge processes consumes a lot of energy, resulting in high treatment costs (Bai et al., 2004).

Phyllosphere bacteria often have a positive influence upon plant, where they may be involved in the fixation of nitrogen, promoting the growth of plants, or the control of plant pathogens. However, some high infectivity fungi may damage many economically important crops and trees, and bring a significant risk and safety concerns for the food supplies. Although chemical control agents have been used world widely, the biological control agents have attracted a great R\&D interest because of their potential for long-term application as environmental friendly agents (Ten Hoopen and Krauss, 2006). Biocontrol agents have been used to protect plants against foliar diseases in several crops (Yuen and Schoneweis, 2007; Alvindia and Natsuaki, 2008; Perello et al., 2007). However, many of them are poor competitors for leaf surface nutrients compared with indigenous phyllosphere microbes (Zhang et al., 2008).

Strains of Paenibacillus polymyxa have been isolated from different soils (Ash et al., 1993), rhizospheres and roots from plants cultivated all over the world, and many of them have been described as effective plant growth promoting rhizobacteria (Pichard et al., 1995; Petersen et al., 1996; Lorentz et al., 2006). Untill now, P. polymyxa has been seldom discovered in the phyllosphere. In the present work, a strain of P. polymyxa EBL06 was isolated from wheat phyllosphere, which could restrain the growth of the filamentous fungi. P. polymyxa strains 
have been proved to produce a wide variety of secondary metabolites, including different antibacterial and/or antifungal compounds (von der Weid et al., 2000). Therefore, the antagonistic effect of these strains upon microbial growth suggests a potential application as biological control agents. The aims of this study were to characterize the newly isolated strain of P. polymyxa EBL06 and optimize the production of the bacterium using the sweat potato wastewater (SPW) and the monosodium glutamate wastewater (MGW).

\section{Materials and methods}

\subsection{Isolation and in vitro antagonist assays}

The experiment was conducted in a native field located at the Tongzhou near Beijing City, China. Wheat cultivars were planted in the field in October, 2006, watered and fertilized in accordance to local cultivation practices. Wheat phyllosphere microbes were collected in May, 2007 according to the methods described by Zhang et al. (2008). An anti-fungi bacterial strain EBL06 was isolated on Potato-dextrose Agar (PDA) medium Petri dish, and maintained on the PDA slant tubes. The antagonistic activity of the strain was evaluated by the method of confronting cultures with the filamentous fungi (Foldes et al., 2000; Bai et al., 2008), such as Trichoderma harzimum, Botrytis cinerea, Cladosporium cucumerinum, Fusarium spp., Macrophom spp., which was modified as the following. A point of filamentous fungi was inoculated onto the center of PDA Petri dish; three points of isolation were inoculated at $2 \mathrm{~cm}$ distance from the center of the Petri dish symmetrically. The Petri dish was then incubated at $28{ }^{\circ} \mathrm{C}$ for a few days. The isolated strain was considered to be antagonistic to the filamentous fungus if it restrains the fungi growth with inhibition zone (Fig. 1).

\subsection{Resistance to antibiotics of the Bacteria}

Resistance to antibiotics was determined using standard antibiotic disks. Inhibition diameters were recorded after $24 \mathrm{~h}$ of incubation at $30^{\circ} \mathrm{C}$ under aerobic conditions. The classification of the strain, as sensitive, not sensitive or intermediate sensitive to the antibiotics, was done according to the inhibition diameters. Tests were performed in triplicate.

\subsection{PCR amplification, sequencing, and phylogenetic analysis of the 16S rRNA gene} The primer set 27F-1492R was used in PCR amplification of the 16S rRNA gene fragment of isolate EBL06 under that conditions as described by Kuklinsky et al. (2004). The 16S rDNA was sequenced by Shanghai Sangon Co. Ltd., China. Sequence similarity searches were conducted using the National Center for Biotechnology Information BLAST network service (nucleotide blast). Similar 16S rRNA gene sequences, from previously cultured bacteria, were downloaded from GenBank and manually checked for ambiguous sites using bioedit 7.0.1 software. Alignments were then performed against the 16S rRNA gene sequence of isolate EBL06, where the pair-wise deletion option for gaps was employed. The alignment data were then used for neighbour-joining analysis with 1000 bootstrap replicates (MEGA version 4.0; Arizona State University, USA) (Li et al., 2007).

\subsection{Optimization of culture conditions}

The SPW samples were collected from a sweat potato starch process waste stream in Changsha, China, mainly containing COD $16000 \mathrm{mg} / 1$. The $\mathrm{pH}$ of SPW was 6.2; it was adjusted to 7.0 by $\mathrm{NaOH}$ when the SPW was used as the culture medium. The starch, pectin 
and sugars in the SPW were used as the main carbon source throughout the investigation. The MGW samples were obtained from Henan Lianhua Monosodium Glutamate Co., Ltd., which located in Zhoukou, Henan Province, China. The MGW consisted of $1.20 \%$ total Kjeldahl-N, $1.17 \% \mathrm{NH}_{4}{ }^{+}, 4.06 \% \mathrm{SO}_{4}{ }^{2+}$ and $0.275 \%$ reducing sugar. Trace element components in the MGW were given as follows (mg/l): $\mathrm{Ba}, 0.932 ; \mathrm{Ca}, 389 ; \mathrm{Co}, 0.0123 ; \mathrm{Cu}, 0.605 ; \mathrm{K}, 259$; $\mathrm{Mg}$, 79.0; Pb, 0.588; Sr, 0.869; Zn, 1.80; Mn, 2.66; Fe, 4.28; Na, 794; Cr, 0.862; P, 81.4; V, 0.0082. The $\mathrm{pH}$ of raw MGW 1.5 and was adjusted to 6.7 by $\mathrm{NaOH}$ when the MGW was used as the culture medium. Ammonium in the MGW was used as the main nitrogen source.

The isolate EBL06 was grown on the PDA slants at $30{ }^{\circ} \mathrm{C}$ for 2 days. A single clone was inoculated into $250-\mathrm{ml}$ flask containing $100 \mathrm{ml}$ of the PDA medium at $30^{\circ} \mathrm{C}$ for $24 \mathrm{~h}$. This seed culture was used to initiate the growth in fermentation medium used in this study. The basic medium (BM) is composed of as follows (g/l): $\mathrm{MgSO}_{4} 7 \mathrm{H}_{2} \mathrm{O} 0.10, \mathrm{KH}_{2} \mathrm{PO}_{4} 0.50, \mathrm{NaC} 10.50$, and $\mathrm{K}_{2} \mathrm{HPO}_{4}$ 1.50. The fermentation was conducted in $250 \mathrm{ml}$ Erlenmeyer flasks containing $100 \mathrm{ml}$ medium inoculated with $5 \mathrm{ml}$ of seed culture. Unless otherwise was stated, the agitation rate and incubation temperature were $200 \mathrm{r} / \mathrm{min}$ and $30^{\circ} \mathrm{C}$, respectively.

All experiments were conducted in duplicate and the average values are reported. Key results were repeated three times to establish their validity.

\section{Results}

\subsection{Morphology and antagonistic fungus activity of the isolate EBL06}

Microscopic observation of the isolate EBL06 is a mesophilic, Gram-positive and motile bacterium, and cells are rod-shaped with peritrichous flagella in overnight culture in PD medium at $30{ }^{\circ} \mathrm{C}$ and $150 \mathrm{r} / \mathrm{min}$ using Light-microscophy. The cells are found singly, double, and chains. Colonies of the strain on PDA are slightly yellow, circular, smooth, convex, semi-transparent and $2-3 \mathrm{~mm}$ in diameter with an entire margin after incubation for $48 \mathrm{~h}$ at $30^{\circ} \mathrm{C}$.

EBL06 showed a significant antagonistic activity towards fungal species of Cladosporium cucumerinum, Trichoderma harzimum, Botrytis cinerea, Fusarium spp. and Macrophom spp. on PDA plates. Figure 1 shows two images of the test process.

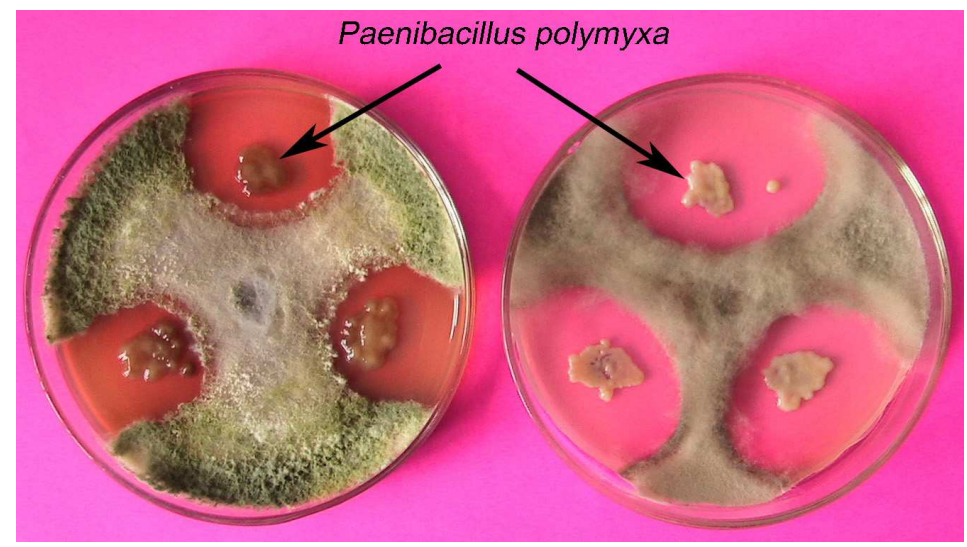

Fig. 1. Growth impact of the isolated EBL06 on the Trichoderma harzimum (left) and Botrytis cinerea (right) at the PDA medium. 


\subsection{Resistance to antibiotics of the isolate EBL06}

The growth behaviour of the isolate EBL06 was studied in the presence of a range of antibiotics. The strain was susceptible to penicillin, streptomycin, kanamycin and tetracycline, and was weakly susceptible to chloramphenicol, and resistant to polymyxine and colistine.

\subsection{Phylogenetic analysis}

To analyze the phylogenetic position, the 16S rDNA sequence of the isolate EBL06 was determined, and a phylogenetic tree was constructed (Fig. 2). The sequence was deposited in the GenBank database under the accession number EF545556. The phylogenetic analysis indicated that the isolate EBL06 is most closely related to species of $P$. polymyxa.

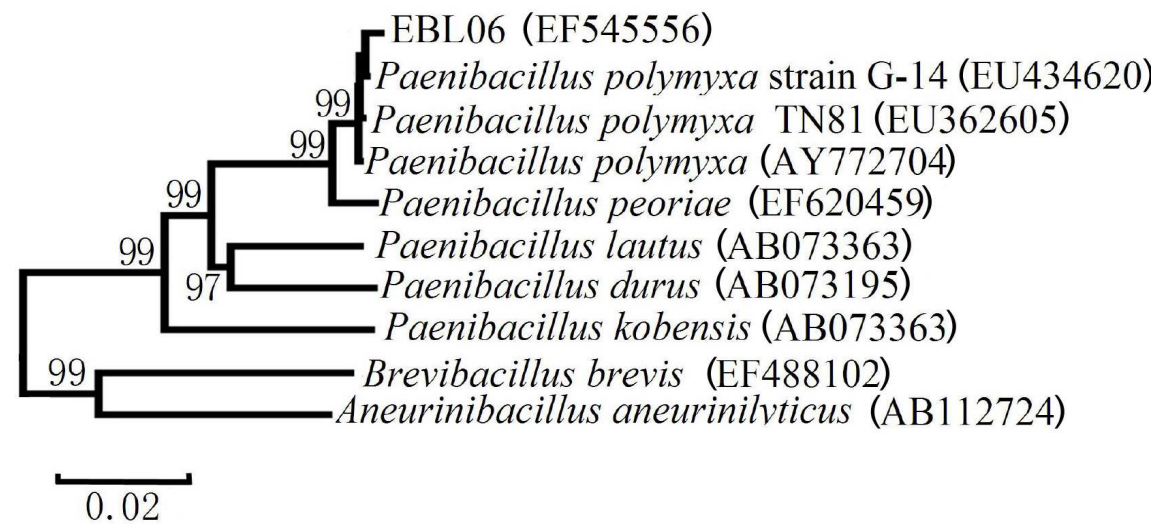

Fig. 2. Neighbor-joining trees showing the phylogenetic position of the isolate EBL06 and its related species based on 16S rRNA gene sequences. The GenBank accession number for each microorganism used in the analysis is shown after the species name. Bootstrap values (expressed as a percentage of 1000 replications) greater than $50 \%$ are shown at the branches.

\subsection{Effect of carbon sources on the isolate EBL06 growth}

The fermentation medium contained $10 \mathrm{ml} \mathrm{MGW}, 90 \mathrm{ml} \mathrm{BM}$, and 2\% each carbon sources, including sugar, D-glucose, soluble starch, and SPW $(90 \mathrm{ml}$, the carbon source equal to $2 \mathrm{~g}$ starch, no BM). After inoculation with $2 \mathrm{ml}$ of inoculum, the medium was incubated at $30^{\circ} \mathrm{C}$ for $20 \mathrm{~h}$. The effect of carbon sources on the production of the isolate EBL06 are presented in Fig. 3. It was found that SPW are the most suitable carbon source.

\subsection{Effect of nitrogen sources on the isolate EBL06 growth}

The fermentation medium contained $90 \mathrm{ml} \mathrm{SPW}$ as carbon source, $10 \mathrm{ml} \mathrm{BM}$, and $0.5 \%$ different nitrogen sources, including corn steep liquor, potassium nitrate, ammonium sulfate and MGW (10 ml, the nitrogen source equal to $0.5 \mathrm{~g}\left(\mathrm{NH}_{4}\right)_{2} \mathrm{SO}_{4}$, no $\left.\mathrm{BM}\right)$. A control experiment was conducted without addition of nitrogen source. After inoculation with $2 \mathrm{ml}$ of inoculum, the medium was incubated at $30{ }^{\circ} \mathrm{C}$ for $20 \mathrm{~h}$. The results of impact of nitrogen sources on the production of the isolate EBL06 are presented in Fig. 4. It was found that corn steep liquor and MGW were the most efficient nitrogen sources for production of the strain. Comparing with the corn steep liquor, MGW are the most suitable nitrogen source due to the low cost. 


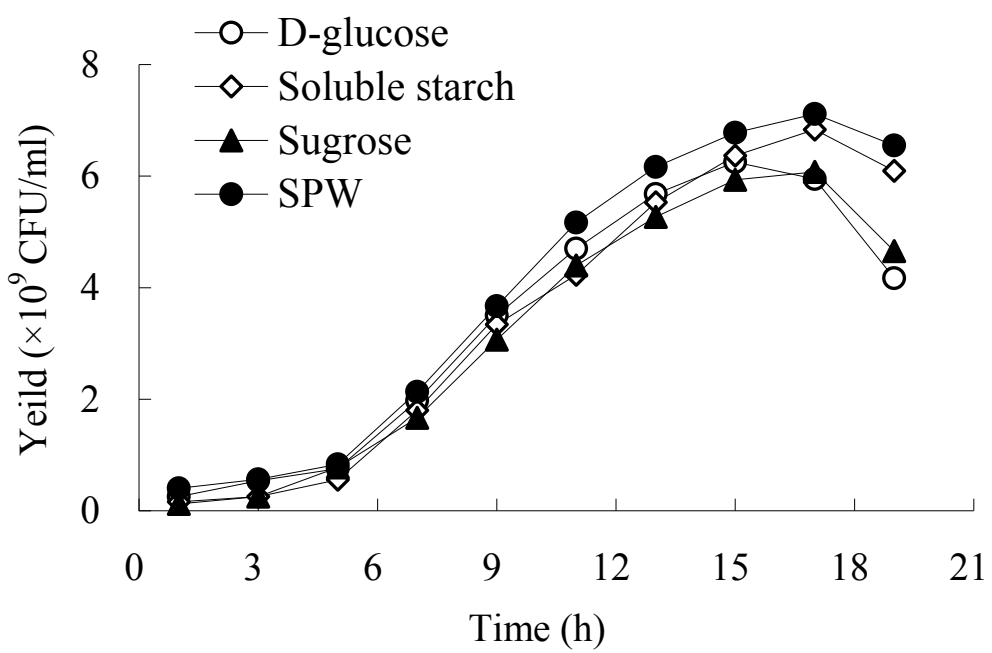

Fig. 3. Effect of different carbon sources on the isolate EBL06 growth.

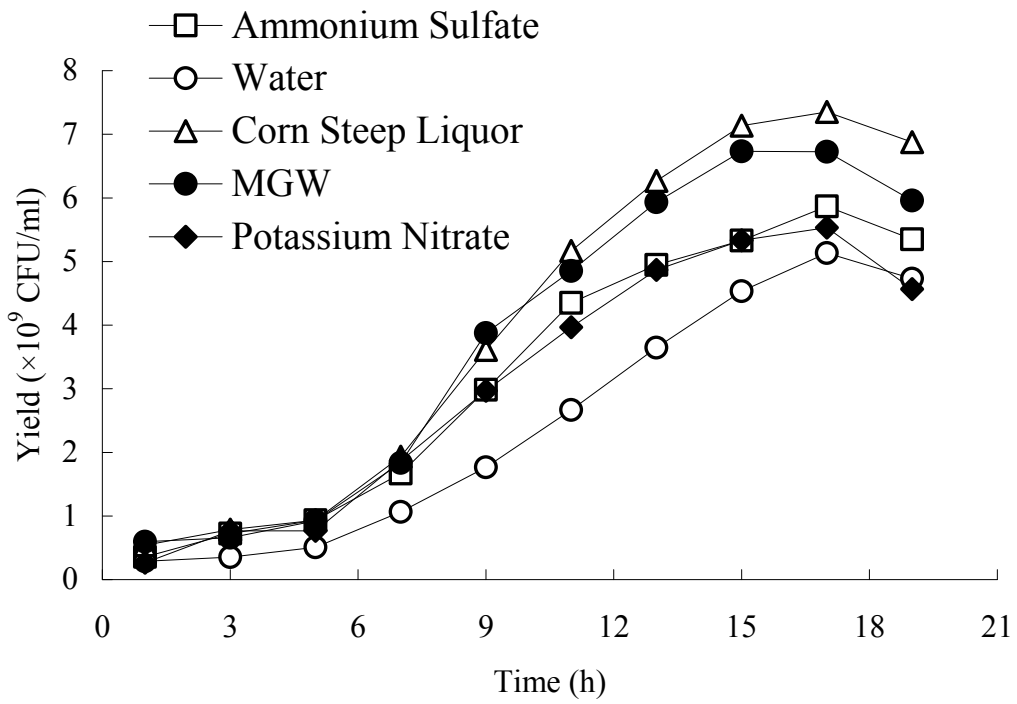

Fig. 4. Effect of different nitrogen sources on the isolate EBL06 growth.

\subsection{Effect of $\mathrm{pH}$ on the isolate EBL06 growth}

The fermentation medium contained $10 \mathrm{ml} \mathrm{MGW}, 90 \mathrm{ml}$ SPW. After inoculation with $2 \mathrm{ml}$ of inoculum, the medium was incubated at $\mathrm{pH}$ 5.5, 6.0, 6.5, 7.0, 7.5 and 8.0 respectively. The 
isolate EBL06 production at different $\mathrm{pH}$ is shown in Fig. 5. The highest yield could be given at $\mathrm{pH}$ 6.5--7.0 after $15 \mathrm{~h}$ fermentation. Consequently, $\mathrm{pH} 7.0$ was selected in the following experiment.

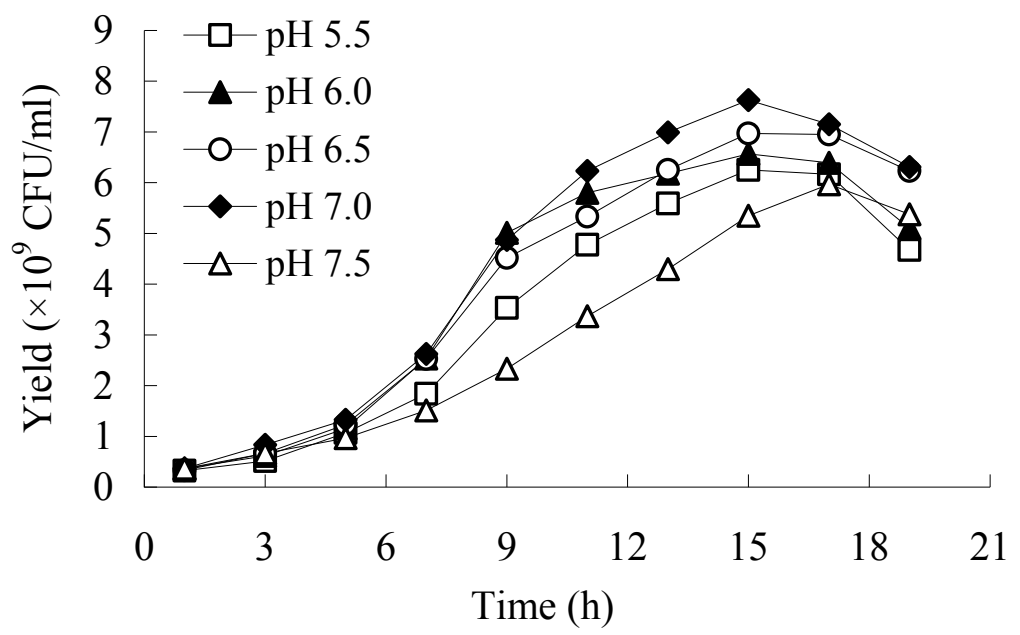

Fig. 5. Effect of initial culture medium $\mathrm{pH}$ on the isolate EBL06 growth.

\subsection{Effect of culture temperature on the isolate EBL06 production}

The fermentation medium contained $10 \mathrm{ml} \mathrm{MGW}, 90 \mathrm{ml}$ SPW. After inoculation with $2 \mathrm{ml}$ of inoculum, the medium was incubated at $24,28,32,36$ and $40{ }^{\circ} \mathrm{C}$, respectively. The time courses of the isolate EBL06 production at different temperature are shown in Fig. 6. The maximum yield of $7.3 \times 10^{9} \mathrm{CFU} / \mathrm{ml}$ was reached at $32{ }^{\circ} \mathrm{C}$ after $15 \mathrm{~h}$ fermentation.

\section{Disscussion}

P. polymyxa endospore was reported to be resistant to desiccation, heat, and UV irradiation, and have excellent biochemical characteristics that allow for further formulation and commercialization procedures. Previous studies have shown that strains of $P$. polymyxa can produce different peptide antimicrobial substances (Rosado and Seldin, 1993; Piuri et al., 1998; Dijksterhuis et al., 1999; Seldin et al., 1999). The peptide metabolites are generally classified into two groups according to their antimicrobial activities. The first group includes the polypeptins, polymyxins, jolipeptin, gavaserin, and saltavalin, which showed antibacterial activity against both gram-negative and gram-positive bacteria. The second group consists of a single family of closely related peptides variously designated gatavalin, fusaricidins, all of which contain an unusual fatty acid side chain, 15-guanidino-3-hydroxypentadecanoic acid (Raza et al., 2009). As a phyllosphere isolate, P. polymyxa EBL06 could be suitable to survive in the phyllosphere conditions; the antagonistic fungi ability also give them a growth advantage in the competitive environment. $P$. polymyxa EBL06 showed a significant antagonistic activity towards all the filamentous fungi tested. It will be used as a potential biocontrol agent for protecting plant against fungal disease in further study. 


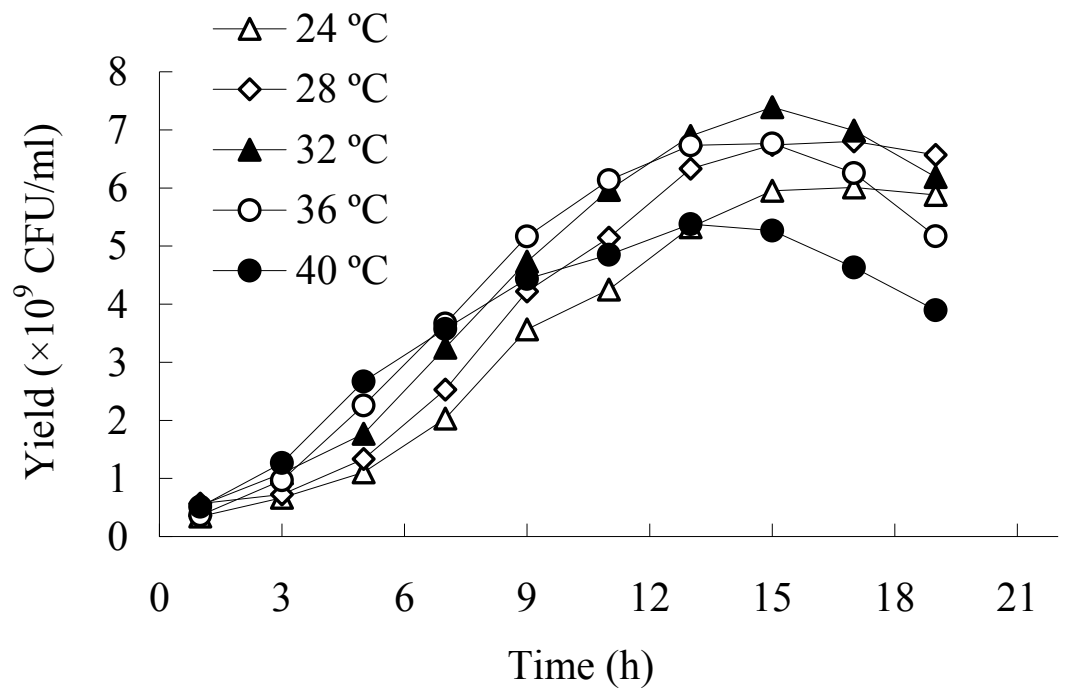

Fig. 6. Effect of culture temperature on the isolate EBL06 growth

MGW is one of the most intractable wastewater because of its high strength of COD, ammonium and sulphate (Yang et al., 2005). SPW also contains high COD and nutrient loadings. A few studies have already focused on the utilization of such high organic loading wastewater as substrates or production media in fermentation processes (Bai et al., 2004; Mishra et al., 2004; Huang et al., 2005). As far as the authors are aware, no papers have been published on utilization of both MGW and SPW in one process. In the present study, the isolate EBL06 could use well the starch in the SPW as the main carbon source, and ammonium in the MGW as the main nitrogen source. In addition, the nutrient and trace element components in the wastewaters are also suitable for the isolate EBL06 growth. Compared with other culture media, the mixture of SPW and MGW is the most suitable for the biocontrol agent production from the economic and environmental point of view.

$P$. polymyxa has also been isolated from several places such as food, rhizosphere, poultry production environments, soils and most of them can restrain fungal pathogen growth (He et al., 2007; Raza et al., 2009; Svetoch et al., 2005). Further studies will investigate the antifungal pathogen activity of the isolate EBL06 both in phyllosphere and in rhizosphere by field trials. Further understanding of the survival strategy of the isolate EBL06 in phyllosphere might improve the efficiency of the biological treatments and also lead to enhanced yields of agricultural crops.

In conclusion, a newly isolated P. polymyxa EBL06 from wheat phyllosphere can be used as a nonchemical alternative biocontrol agent against plant disease caused by fungal pathogen. A novel process for economical production of $P$. polymyxa biocontrol agent was developed using MGW and SPW. It is feasible to develop a hybrid biotechnological process, integrating the production of environmental friendly biocontrol agent with treatment of intractable wastewater. 


\section{Acknowledgments}

This work was supported by the "Knowledge Innovation" Program of Chinese Academy of Sciences (No KSCX2-YW-G-054-2) and the Key Technologies R\&D Program of China (Nos. 2009BAC57B02 and 2008BADA7B01).

\section{References}

Alvindia D G, Natsuaki K T, 2008. Evaluation of fungal epiphytes isolated from banana fruit surfaces for biocontrol of banana crown rot disease. Crop Protection, 27(8): 1200-1207.

Ash C, Priest F G, Collins M D, 1993. Molecular identification of rRNA group 3 bacilli (Ash, Farrow, Wallbanks and Collins) using a PCR probe test. Antone Van Leeuwenhoek International Journal of General and Molecular Microbiology, 64(3-4): 253--260.

Bai Z H, Zhang H X, Qi H Y, Peng X W, Li B J, 2004. Pectinase production by Aspergillus niger using wastewater in solid state fermentation for eliciting plant disease resistance. Bioresource Technology, 95(1): 49--52.

Bai Z H, Jin B, Li Y J, Chen J, Li Z M, 2008. Utilization of winery wastes for Trichoderma viride biocontrol agent production by solid state fermentation. Journal of Environmental Sciences, 20(3): 353--358.

Dijksterhuis J, Sander M, Gorris L G M, Smid E J, 1999. Antibiosis plays a role in the context of direct interaction during antagonism of Paenibacillus polymyxa towards Fusarium oxysporum. Journal of Applied Microbiology, 86(1): 13--21.

Foldes T, Banhegyi I, Herpai Z, Varga L, Szigeti J, 2000. Isolation of Bacillus strains from the rhizosphere of cereals and in vitro screening for antagonism against phytopathogenic, food-borne pathogenic and spoilage micro-organisms. Journal of Applied Microbiology, 89(5): 840--846.

He Z G, Kisla D, Zhang L W, Yuan C H, Green-Church K B, Yousef A E, 2007. Isolation and identification of a Paenibacillus polymyxa strain that coproduces a novel lantibiotic and polymyxin. Applied and Environmental Microbiology, 73(1): 168--178.

Kuklinsky S J, Araujo W L, Mendes R, Geraldi I O, Pizzirani K A A, Azevedo J L, 2004. Isolation and characterization of soybean-associated bacteria and their potential for plant growth promotion. Environmental Microbiology, 6(12): 1244--1251.

Huang L P, Jin B, Lant P, 2005. Direct fermentation of potato starch wastewater to lactic acid by Rhizopus oryzae and Rhizopus arrhizus. Bioprocess and Biosystems Engineering, 27(4): 229--238.

Li X, Ma X H, Zhao Y H, Jia X M, Kai L, Guo K P, Zhao W F, 2007. Isolation and characterization of a new bacterium capable of biotransforming cis-epoxysuccinic acid to D(-)-tartaric acid. FEMS Microbiol Letters, 267(2): 214--220.

Lindow S E, Brandl M T 2003. Microbiology of the phyllosphere. Applied and Environmental Microbiology, 69(4): 1875--1883.

Lindow S E, Leveau J H, 2002. Phyllosphere microbiology. Current Opinion in Biotechnology, 13(3): 238--243. 
Lorentz R H, Artico S, da Silveira B A, Einsfeld A, Corcao G, 2006. Evaluation of antimicrobial activity in Paenibacillus spp. strains isolated from natural environment, Letters in Applied Microbiology, 43(5):541--547

Mishra B K, Arora A, Lata, 2004. Optimization of a biological process for treating potato chips industry wastewater using a mixed culture of Aspergillus foetidus and Aspergillus niger. Bioresource Technology, 94(1): 9--12.

Piuri M, Sanchez-Rivas C, Ruzal S M, 1998. A novel antimicrobial activity of a Paenibacillus polymyxa strain isolated from regional fermented sausages. Letters in Applied Microbiology, 27(1): 9--13

Perello A, Moreno V, Monaco C, Simon M R, 2007. Effect of Trichoderma spp. isolates for biological control of tan spot of wheat caused by Pyrenophora tritici-repentis under field conditions in Argentina. BioControl, 53(6): 895--904.

Petersen D J, Srinivasan M, Chanway C P, 1996. Bacillus polymyxa stimulates increased Rhizobium etli populations and nodulation when co-resident in the rhizosphere of Phaseolus vulgaris. FEMS Microbiology Letters, 142(2-3): 271--276.

Pichard B, Larue J P, Thouvenot D, 1995. Gavaserin and saltavalin, new peptide antibiotics produced by Bacillus polymyxa, FEMS Microbiology Letters, 133(3): 215--218.

Raza W, Yang X, Wu, H, Wang Y, Xu Y, Shen Q, 2009. Isolation and characterisation of fusaricidin-type compound-producing strain of Paenibacillus polymyxa SQR-21 active against Fusarium oxysporum f. sp nevium. European Journal of Plant Pathology, 125(3): 471--483.

Rosado A S, Seldin L, 1993. Production of a potentially novel anti-microbial substance by Bacillus polymyxa. World Journal of Microbiology and Biotechnology, 9(5): 521--528.

Seldin L, Azevedo F S, Alviano D S, Alviano C S, Bastos M C F, 1999. Inhibitory activity of Paenibacillus polymyxa SCE2 against human pathogenic micro-organisms. Letters in Applied Microbiology, 28(6): 423--427.

Svetoch E A, Stern N J, Eruslanov B V, Kovalev Y N, Volodina L I, Perelygin V V, Mitsevich E N, Mitsevich I P, Pokhilenko V D, Borzenkov V N, Levchuk V P, Svetoch O E, Kudriavtseva T Y, 2005. Isolation of Bacillus circulans and Paenibacillus polymyxa strains inhibitory to Campylobacter jejuni and characterization of associated bacteriocins. Journal of Food Protection, 68(1): 11--17.

ten Hoopen G M, Krauss U, 2006. Biology and control of Rosellinia bunodes, Rosellinia necatrix and Roselliia pepo: A review. Crop Protection, 25(2): 89--107.

von der Weid I, Paiva E, Nobrega A, van Elsas J D, Seldin L, 2000. Diversity of Paenibacillus polymyxa strains isolated from the rhizosphere of maize planted in Cerrado soil. Research in Microbiology, 151(5): 369--381.

Yang Q, Yang M, Zhang S, Lv W, 2005. Treatment of wastewater from a monosodium glutamate manufacturing plant using successive yeast and activated sludge systems. Process Biochemistry, 40(7): 2483--2488.

Yuen G Y, Schoneweis S D, 2007. Strategies for managing Fusarium head blight and deoxynivalenol accumulation in wheat. International Journal of Food Microbiology, 119(1-2): 126--130.

Zhang B G, Bai Z H, Hoefel D, Tang L, Yang Z G, Zhuang G Q, Yang J Z, Zhang H X, 2008. Assessing the impact of the biological control agent Bacillus thuringiensis on the 
indigenous microbial community within the pepper plant phyllosphere. FEMS microbiology letters, 284(1): 102--108.

Zhang B G, Zhang H X, Jin B, Tang L, Yang J Z, Li B J, Zhuang G Q, Bai Z H, 2008. Effect of cypermethrin insecticide on the microbial community in cucumber phyllosphere. Journal of Environmental Sciences, 20(11): 1356--1362. 


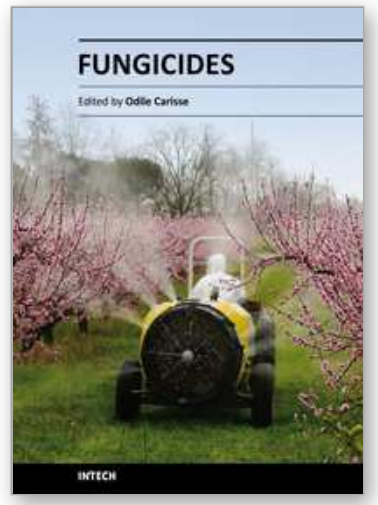

\author{
Fungicides \\ Edited by Odile Carisse
}

ISBN 978-953-307-266-1

Hard cover, 538 pages

Publisher InTech

Published online 14, December, 2010

Published in print edition December, 2010

Plant and plant products are affected by a large number of plant pathogens among which fungal pathogens. These diseases play a major role in the current deficit of food supply worldwide. Various control strategies were developed to reduce the negative effects of diseases on food, fiber, and forest crops products. For the past fifty years fungicides have played a major role in the increased productivity of several crops in most parts of the world. Although fungicide treatments are a key component of disease management, the emergence of resistance, their introduction into the environment and their toxic effect on human, animal, non-target microorganisms and beneficial organisms has become an important factor in limiting the durability of fungicide effectiveness and usefulness. This book contains 25 chapters on various aspects of fungicide science from efficacy to resistance, toxicology and development of new fungicides that provides a comprehensive and authoritative account for the role of fungicides in modern agriculture.

\title{
How to reference
}

In order to correctly reference this scholarly work, feel free to copy and paste the following:

Zhihui Bai, Likun Gu, Yanming Su, Bo Jin and Guoqiang Zhuang (2010). Utilization of Sweat Potato Starch Wastewater and Monosodium Glutamate Wastewater for Cultivation of an Anti-Fungal Biocontrol Agent Paenibacillus Polymyxa, Fungicides, Odile Carisse (Ed.), ISBN: 978-953-307-266-1, InTech, Available from: http://www.intechopen.com/books/fungicides/utilization-of-sweat-potato-starch-wastewater-and-monosodiumglutamate-wastewater-for-cultivation-of

\section{INTECH}

open science | open minds

\section{InTech Europe}

University Campus STeP Ri

Slavka Krautzeka 83/A

51000 Rijeka, Croatia

Phone: +385 (51) 770447

Fax: +385 (51) 686166

www.intechopen.com

\section{InTech China}

Unit 405, Office Block, Hotel Equatorial Shanghai

No.65, Yan An Road (West), Shanghai, 200040, China

中国上海市延安西路65号上海国际贵都大饭店办公楼 405 单元

Phone: +86-21-62489820

Fax: $+86-21-62489821$ 
(C) 2010 The Author(s). Licensee IntechOpen. This chapter is distributed under the terms of the Creative Commons Attribution-NonCommercialShareAlike-3.0 License, which permits use, distribution and reproduction for non-commercial purposes, provided the original is properly cited and derivative works building on this content are distributed under the same license. 